\title{
PRODUÇÃO ACADÊMICA EM RECURSOS HUMANOS NO BRASIL: 1991-2000
}

\section{RESUMO}

O crescimento da produção acadêmica em Administração no Brasil desde 1980 tem incentivado a publicação recente de muitos balanços críticos, como os realizados pelas áreas de Organizações, Marketing, Administração da Informação e Administração Pública. O presente artigo faz um balanço da produção em Recursos Humanos na década de 1990, publicada nos principais periódicos científicos brasileiros (RAUSP, RAP, RAE e RAC) e no Enanpad. O artigo levanta e analisa temática, base epistemológica, orientação metodológica e demografia de autoria de todos os 127 artigos publicados nos periódicos e os 290 veiculados no Enanpad no período. Os resultados indicam que, embora a produção da área tenha aumentado significativamente em volume, o perfil acadêmico de RH no Brasil é preocupante: seu escopo temático é contestado pelo recente crescimento e autonomia do campo de comportamento organizacional; sua base epistemológica é eminentemente funcionalista; a base metodológica é frágil, predominando estudos de caso tipicamente ilustrativos de teoria consolidada (ou seja, sem maior pretensão de indução ou criação de teoria); e a diversidade de origem é baixa: mais de 65\% da produção vem de apenas 7 programas de pós-graduação.

\section{Maria José Tonelli \\ FGV-EAESP \\ Miguel P. Caldas \\ FGV-EAESP}

\section{Beatriz Maria Braga Lacombe \\ FGV-EAESP e FEA-USP}

\section{Tatiana Tinoco}

FGV-EAESP

\begin{abstract}
The growth in academic research in Business Administration in Brazil since 1980 has been recently investigated and questioned in several meta-studies, as can be found in the areas of Organization Theory, Marketing, Information Technology and Public Administration. Following this trend, this paper evaluates the academic production in Human Resources area in de the 90s. Representative academic research was considered to be the articles published in the most important brazilian journals - RAUSP, RAP, RAE and RAC - and presented at the Enanpad. For the 127 articles published in the periodicals and the 290 presented at the Enanpads, the paper investigates 4 variables: themes of interest, epistemological basis, methodological orientation and authorship. The results indicate that, even though production has significantly increased, the area has some serious issues to worry about: the thematic scope has been more and more disputed with Organizational Behavior area; the functionalist paradigm clearly dominates the scenario; methodological basis show problems as well, with an extensive utilization of single, illustrative case studies that merely replicates consolidated theory and that have, clearly, no intention of theory generation; low diversity in origin: more than 65\% of the articles come from only 7 institutions.
\end{abstract}

PALAVRAS-CHAVE Produção acadêmica em RH, balanço crítico, epistemologia, metodologia, temática em RH, autores em RH. KEY WORDS Academic production in HR, critical meta-study, epistemology, methodology, themes in HR, authors in HR. 


\section{INTRODUÇÃo}

É inegável que, nas últimas duas décadas, o crescimento quantitativo da produção acadêmica em administração no Brasil foi significativo. Considerando-se somente a década de 1990, com o aumento da pressão da Capes pela produção docente e discente, o crescimento em volume foi ainda mais notável: contando-se apenas a produção nos principais periódicos científicos da área (RAUSP, RAP, RAE e RAC), o crescimento em número de trabalhos foi de 46,4\%. No mesmo período, o aumento do número de artigos aceitos no Enanpad foi de 144,3\%. Quando somados os dois canais de veiculação (periódicos e anais do Enanpad), podemos afirmar que a produção acadêmica no Brasil cresceu em 105,7\% somente na década de 1990.

O crescimento quantitativo trouxe também o crescimento da preocupação com a qualidade da produção, e com a sua inexpressividade internacional (Bertero, Caldas e Wood, 1999). Esse tipo de preocupação foi materializado, principalmente, por uma onda de balanços retrospectivos, essencialmente críticos, feitos a partir de 1990, e mais intensamente após 1997.

\section{Balanços Críticos da Produção Acadêmica Brasileira em Administração}

O trabalho pioneiro de Machado-da-Silva, Cunha e Amboni (1990) parece ser aquele que despertou a academia de Administração para a necessidade de uma ampla avaliação de sua produção. Os autores fizeram uma avaliação dos artigos da área de Organizações, a partir de artigos publicados em periódicos, no período de 1985 a 1989, concluindo pela fragilidade teóricometodológica da área no período, e pelo predomínio de uma orientação funcionalista.

A partir desse primeiro levantamento, várias áreas passaram a fazer balanços críticos desse tipo, como a de Marketing (Vieira, 1998, 1999, 2000; Perin et al., 2000; Botelho e Macera, 2000), a de Administração da Informação (Hoppen et al., 1998), Produção (Bignetti e Paiva, 1997) e a de Administração Pública (Keinert, 2000). O que chama a atenção em praticamente todos estes estudos é a convergência da conclusão: quase todos indicam problemas sérios na qualidade dos trabalhos.

Também na área de Organizações, o trabalho de Bertero e Keinert (1994) avaliou artigos publicados na Revista de Administração de Empresas (RAE), no período de 1961 a 1993. Segundo esses autores, os artigos do período na área de Análise Organizacional reproduzem, de modo geral, a temática estrangeira, e não há originalidade nem a reflexão sobre a aplicabilidade dos conceitos para a realidade brasileira.

Já na área de Marketing, Vieira (1998, 1999, 2000), realizou um amplo balanço crítico. No trabalho de 1998 , o autor mostrou, ao avaliar os artigos publicados nos Anais do Enanpad durante a década de 1990, que os temas pesquisados estavam voltados para Comportamento do Consumidor, Estratégia de Mercado, Marketing de Serviços e Sistema de Informação de Pesquisa em Marketing, e que a produção acadêmica dessa área concentra-se na UFRGS, na USP e na UFRJ. No trabalho de 2000, o autor traça um panorama sobre aspectos qualitativos dos trabalhos em Marketing, mostrando que, ainda que tenha crescido nos últimos anos, a área apresenta questões sérias relativas à qualidade de sua produção. Ainda na área de Marketing, Perin et al. (2000) afirmam que a análise de pesquisas empíricas do tipo survey nessa área, publicadas na década de 90 nos anais dos Enanpad, têm qualidade, no mínimo, questionável. O artigo de Botelho e Macera (2000), que analisou teses e dissertações produzidas na FGV-EAESP, no período de 1974 a 1999, sugere que a área é caracterizada pela ausência de uma avaliação meta-teórica.

Conclusões semelhantes repetem-se na área de Administração da Informação. O trabalho de Hoppen et al. (1998) mostrou que, dos 163 artigos publicados nessa área em revistas científicas no período entre 1990 e 1997 , $41 \%$ são ensaios e, dos trabalhos empíricos, $72 \%$ são do tipo "survey". Entretanto, dizem os autores, sejam os estudos qualitativos ou quantitativos, a qualidade da produção é baixa.

Outros balanços e meta-estudos retrospectivos ou não se concentraram em uma única área, ou foram focados em um aspecto específico da produção analisada, como o perfil metodológico, por exemplo. Nessa linha, Martins (1997) pesquisou as abordagens metodológicas das teses e dissertações produzidas entre 1980 e 1993 em três programas de pós-graduação em Administração (FEAUSP, FGV-EAESP, FEA-PUC). O autor mostrou que os trabalhos são, em sua maioria, empiricistas, positivistas e funcionalistas.

Um outro tipo de meta-estudo que se tornou popular é o que avalia o tipo, origem e padrão de citações da produção científica. O trabalho pioneiro de Vergara e Carvalho Jr. (1995) teve importante papel na difusão desse tipo de balanço. Esses autores estudaram as referências bibliográficas de artigos em Organizações: seus resultados mostraram que os autores brasileiros da área usam preferencialmente livros e artigos estrangeiros predominantemente americanos e ingleses - e, quando 
se trata de periódicos, a predominância é de revistas norte-americanas. As referências aos autores brasileiros é minoria. Cinco anos depois, Vergara e Pinto (2000) atualizaram e expandiram o meta-estudo, chegando a conclusões semelhantes: as referências naquela área ainda eram predominantemente norte-americanas; no entanto, essa segunda edição do meta-estudo ressalta, positivamente, o aumento do número de autores nacionais referenciados (40\%).

\section{A Produção Acadêmica \\ Brasileira em Recursos Humanos}

A produção acadêmica na área de Recursos Humanos é recente no Brasil. Até a década de 1980, a pesquisa era escassa e pontual, sendo quase toda a literatura "importada" e, portanto, não representativa dos problemas da nossa realidade. A partir dos anos 1980, devido, em parte, à maior visibilidade que Recursos Humanos ganha no contexto internacional e à criação da área no Enanpad - Encontro Nacional de Pós-Graduação em Administração no Brasil - em 1982, que desperta um crescente interesse da academia pela área e os temas a ela relacionados.

A despeito de um crescimento quantitativo significativo e da difusão de balanços críticos e meta-estudos nas demais áreas, até 2002 a área de RH ainda não tinha feito um levantamento exaustivo de sua produção científica, embora dois estudos (Siqueira, 1988; Roesch, Antunes e Silva, 1997) tenham procurado iniciar e incentivar esse tipo de levantamento.

Em seu estudo pioneiro da área, Siqueira (1988) faz um levantamento inicial sobre a produção nos primeiros cinco anos da área no Enanpad: 1982 a 1987. A autora mostra que, para o período analisado, há um crescimento em volume de trabalhos, e sugere que o crescimento da administração de RH no Brasil estaria ligado ao desenvolvimento industrial do país. Foi esse mesmo processo que teria levado ao aumento dos cursos de pósgraduação em Administração no Brasil e à criação da Anpad e do Enanpad. Os artigos foram classificados por Siqueira em duas categorias, técnico/descritivos ou analíticos: os resultados mostraram que há um equilíbrio entre os dois tipos ( $47,8 \%$ e $52,2 \%$ respectivamente). A autora avalia também as temáticas dos artigos da amostra. Embora com alguma variação ao longo dos anos, os resultados mostram que: tecnologia e RH $(20,5 \%)$, negociações coletivas e sindicalismo $(14,5 \%)$, políticas de RH $(14,5 \%)$ e compensação $(11,6 \%)$ foram os sub-temas mais freqüentes. Ainda nesse trabalho, a autora também aponta para o fato de que as instituições que mais apresentaram trabalhos na área foram a FEA-USP e UFRGS. Apesar do seu pioneirismo e evidente contribuição, o escopo do trabalho de Siqueira não alcança as profundas mudanças vividas pela área na década de 1990, o que justifica nos dias de hoje sua extensão e complemento.

Além de Siqueira (1988), a pesquisa de Roesch, Antunes e Silva (1997) também procurou avaliar a relevância da pesquisa na área de Recursos Humanos e Organizações, a partir da análise de 74 dissertações de mestrado, nas décadas de 1980 e 1990. Os autores mostram que existe uma predominância de estudos quantitativos em RH - em contraposição ao predomínio de estudos qualitativos em Organizações- e comentam que esse tipo de pesquisa, isto é, que faz uso de estudos de casos com métodos quantitativos, não permite generalizações e é pouco relevante quando é considerada a abrangência dos seus resultados.

Parece evidente que, à luz da abrangência temporal e de profundidade de análise dos balanços críticos das demais áreas, o campo de Recursos Humanos ainda não tinha feito, até 2002, uma avaliação crítica aprofundada de sua produção científica. Os dois balanços anteriores, apesar de altamente contributivos, ou oferecem dados não recentes (Siqueira, 1988) ou fazem uma avaliação não exaustiva de toda a produção científica da área no Brasil (Roesch, Antunes e Silva, 1997).

Assim, o presente trabalho pretende colaborar para uma avaliação mais extensiva e aprofundada da área (que sem dúvida ainda não se esgota com este estudo), usando todos os estudos referenciados anteriormente como fontes de inspiração, tanto quanto para a metodologia utilizada, como quanto para as variáveis pesquisadas. Como produto, o presente estudo apresenta, essencialmente, um perfil da produção acadêmica na área de Recursos Humanos, a partir da análise de todos os artigos publicados em periódicos científicos e anais do Enanpad, na década de 1990.

O restante do artigo está dividido da seguinte maneira: a seguir, na seção Metodologia da Investigação, são apresentados os critérios utilizados na análise das variáveis temática, base epistemológica, perfil metodológico e demografia de autoria. Na seção de Resultados, mostra-se a produção da área de RH em relação ao total de produção na área, o total de artigos de RH publicados no período analisado, bem como todos os resultados obtidos para as variáveis pesquisadas e já assinaladas anteriormente. Finalmente, na conclusão, argumenta-se que os resultados obtidos são preocupantes, e embora a 
área de RH tenha crescido em volume, esse crescimento não foi acompanhado por qualidade e rigor científico.

\section{METODOLOGIA DA INVESTIGAÇÃO}

A base de dados da pesquisa foi constituída a partir de todos os artigos de Recursos Humanos publicados, entre 1991 e 2000, em dois tipos de publicação: as principais revistas acadêmicas de Administração no Brasil (127 artigos, no total) e os anais do Enanpad (290 artigos, no total). Foram analisados os seguintes periódicos: Revista de Administração de Empresas (RAE), Revista de Administração Pública (RAP), Revista de Administração da USP (RAUSP) e Revista de Administração Contemporânea (RAC). A escolha desses periódicos deveu-se ao fato de que outros estudos (Machado-da-Silva, Cunha e Amboni (1990); Vieira (2000); Hoppen et al. (1998), por exemplo) já fizeram uso dessas revistas como as principais publicações em Administração no país ${ }^{1}$. A pesquisa incluiu também todos os artigos publicados na área de RH nos anais do Enanpad, para o mesmo período.

O presente estudo baseou-se na metodologia de coleta e análise dos mais citados meta-estudos nas diversas áreas do Enanpad, por exemplo, Vieira (1998) e Perin et al. (2000), já mencionados. Para selecionar os artigos de RH dentre todos os publicados nos periódicos foi utilizado o critério proposto por Roesch et al. (1997), já que os trabalhos nem sempre aparecem classificados por área pelos próprios editores.

A principal diferença da presente pesquisa em relação aos meta-estudos mencionados anteriormente, além do foco em RH, é que o intento dos autores com este estudo foi fazer um balanço tão abrangente quanto possível, enfocando para a base analisada a maioria das variáveis analisadas separadamente nos balanços anteriores: (i) temática, (ii) base epistemológica, (iii) perfil metodológico e (iv) demografia de autoria.

No que tange à variável temática, a classificação dos artigos da amostra esbarra, naturalmente, em discussões intermináveis sobre escopo e fronteiras da área de recursos humanos com outros campos de conhecimento, como organizações, comportamento organizacional, psicologia organizacional etc., fazendo da área um território científico contestado, disputado e em crise constante de identidade. Nossos critérios de classificação temática foram, obviamente, afetados por essas limitações históricas do campo. A primeira tentativa de classificação por "clusters" dos artigos a partir da listagem dos temas declarados e das palavras-chave resultou confusa e arbitrária, tendendo a ser enviesada pelo filtro epistemológico e teórico dos codificadores envolvidos. Por esse motivo, preferiu-se fazer uma classificação mais genérica, centrada na diferenciação das grandes tradições temáticas de pesquisa em RH, que em boa parte refletem a própria evolução da área nas últimas décadas. Nesse sentido, foram criadas quatro categorias temáticas arbitrárias, que melhor englobavam os temas exaustivamente listados na base de dados: (a) Funções de Recursos Humanos, (b) Politicas de Gestão de Pessoas, (c) Comportamento Organizacional; e (d) Outros. Foram classificados como de Funções de Recursos Humanos todos os artigos cuja temática referia-se aos chamados "subsistemas" tradicionais de RH, que orientam e regulam as práticas da área nas organizações: recrutamento e seleção, treinamento, avaliação de desempenho etc. A classificação de artigos nesse grupo adotou como base definições clássicas dessa função, tal como revistas, por exemplo, em French (1982) e Devana, Fombrun e Tichy (1984). Artigos codificados como de Políticas de Gestão de Pessoas eram de objetivo ou intento de aplicação organizacional, mas não se focavam nas funções ou "subsistemas" clássicos propriamente ditos, não sendo tampouco reflexivos nem voltados à ação de indivíduos. A classificação nesse grupo foi consistente com a definição desse tipo de enfoque feita por autores como Storey $(1999,2001)$. Os trabalhos classificados como de Comportamento Organizacional tinham como foco o indivíduo e sua relação com a organização, sendo tal classificação baseada na definição de escopo da nova área temática homônima no Enanpad a partir de 2001. Por fim, a classificação em Outros ficou reservada para todos os artigos que não puderam ser classificados nas três temáticas anteriores.

No que tange à variável de base epistemológica, os artigos foram avaliados segundo o seu paradigma preponderante, usando as definições apresentadas por Burrell e Morgan (1979), e seguindo as indicações para este tipo de avaliação feita em estudos similares (Machado-da-Silva, Cunha e Amboni, 1990; Vieira, 1999). Nesse sentido, cada artigo foi categorizado como predominantemente funcionalista, interpretacionista (ou "interpretativo"), humanista radical e estruturalista radical.

O grupo de variáveis de perfil metodológico foi obviamente um dos mais complexos em termos de classificação, e envolveu a categorização dos artigos em várias "camadas" de profundidade, como sugerem estudos semelhantes. Na camada mais genérica, utilizou-se a proposição indicada por Machado-da-Silva, Cunha e 
Amboni (1990), e portanto os artigos foram classificados em: empíricos - aqueles onde não há quadro referencial específico para a explicação das situações reais, a concentração se dá na observação e análise de dados -, teórico-empíricos - compreendendo estudos que partem de um quadro de referências teóricas e, pela coleta de dados, buscam confirmá-lo ou refutá-lo no todo ou em parte - ou teóricos - envolvendo trabalhos que limitam-se a conceitos, proposições, identificação de variáveis, construção ou reconstrução de modelos, sem envolver teste empírico. A categorização de cada artigo segundo esses parâmetros foi também sustentada pelas indicações de Creswell (1998), Eisenhardt (1989), Alvesson e Sköldberg (2000) e Denzin e Lincoln (1994).

A partir dessa classificação metodológica mais genérica, os artigos foram re-agrupados em subclassificações dentro de cada um desses três grupos, tomando como base categorizações propostas por diversos autores. Assim, temos: nos casos em que o artigo foi categorizado como teórico, uma subclassificação foi feita em: (a) ensaio de revisão de teoria existente; (b) ensaio de sistematização de teoria existente; (c) ensaio que constrói ou propõe um conceito ou construto; e (d) ensaio que constrói ou propõe teoria. Tal subclassificação dos artigos teóricos baseou-se na metodologia proposta nos fóruns sobre o tema da Academy of Management Review (1989) e da Administrative Science Quaterly (1995).

Já os artigos teórico-empíricos foram sub-classificados em quantitativos (compreendendo aqueles que usavam modelos estatísticos para análise de dados e suas estratégias incluíam "surveys" e experimentos (Bauer e Gaskell, 2002)) ou qualitativos. Pela relevância e diversidade de sua representação na amostra em análise, os trabalhos categorizados como qualitativos tiveram ainda mais uma sub-classificação, usando as indicações sugeridas por Creswell (2003) e Denzin e Lincoln (1994), assim, esses artigos foram categorizados em:

(a) "Grounded theory", compreendendo os trabalhos que buscam construir teoria a partir da descoberta de padrões, temas ou categorias que surgem a partir dos próprios dados e que, em geral partem de uma teoria, mas sem uma hipótese a ser testada. Nesse tipo de trabalho, conforme os dados adquirem um padrão ou classificação, são comparados com a teoria inicial e, em caso de necessidade, a teoria é reformulada;

(b)Etnometodologia / etnografia, abrangendo os artigos que tinham por foco entender as condições que produzem as interações sociais, assumindo que estas resultam da construção coletiva e da organização das pessoas (Sato, 2001). O método preferido desse tipo de trabalho era a etnografia, ou seja, a observação e a coleta de dados (em geral prolongada no tempo) usando um pesquisador que assume o papel de observador participante, presente e atuante no lugar e no grupo de pessoas que está buscando entender;

(c) Hermenêutica, incluindo trabalhos que recusavam a dicotomia sujeito-objeto, presente nas abordagens positivistas, e que buscavam compreender e interpretar, com ajuda de referenciais teóricos, os sentidos dos fenômenos pesquisados;

(d)Análise de discurso e narrativas, compreendendo os trabalhos de natureza tipicamente pós-estruturalista que, ainda que não tivessem todos a mesma orientação, partilhavam do conceito de que todo pensamento é fundamentalmente mediado pelas relações de poder, que são constituídas histórica e socialmente. Tipicamente, nesses artigos, a relação entre conceito e objeto e significante e significado não é fixa ou estável, e a linguagem é estudada por ser entendida como central para a formação da subjetividade; $\mathrm{e}$

(e) Estudos de caso, abrangendo aqueles trabalhos que faziam uma exploração de uma situação real particular (ou múltiplas situações comparadas), pontualmente ou ao longo do tempo, feita por meio de coleta detalhada e aprofundada de dados, envolvendo múltiplas fontes de informação: documentos, entrevistas, questionários e observação.

Por ser o estudo de caso o tipo específico de trabalho qualitativo mais representativo na amostra, os estudos de caso foram também sub-classificados, usando-se, neste caso, as indicações propostas por Eisenhardt (1989) e Yin (1998), que visam diferenciar trabalhos em função de sua complexidade e nível de contribuição científica. Esses autores lembram que os casos explanatórios e descritivos trazem baixa contribuição científica, o que pode ser agravado para os estudos de amostra única, que não permitem a triangulação dos dados obtidos. Por outro lado, estudos de casos múltiplos e de natureza exploratória trariam melhor contribuição. Assim, os estudos de caso ainda receberam as seguintes classificações: (i) único ou (ii) múltiplo (a partir de três eventos ou organizações estudadas) e, em seguida, como: (a) caso explanatório (aqueles que, a partir de alguma teoria estabelecida, busca relações causais em ocorrências ou eventos, ilustrando teoria existente); (b) caso descritivo (são os que apenas relatam o fluxo de eventos em uma situação ou ocorrência, não ilustrando teoria existente e muito menos criando teoria); ou caso exploratório (aqueles que procuram criar ou propor teoria 
indutivamente, a partir das situações particulares estudadas)

Por fim, a variável demografia de autoria seguiu uma variação do procedimento adotado por Vergara e Carvalho Jr. (1995): a categorização da origem dos autores e instituições dos trabalhos na amostra foi feita usando o critério de proporcionalidade. Com esse critério, atribuiu-se 1 para o autor que publicou ou apresentou um artigo sozinho; $1 / 2$ para cada autor, quando há 2 autores; $1 / 3$, quando há 3 autores; e assim por diante. A mesma proporção foi atribuída à instituição à qual o(s) autor(es) estava(m) filiado(s) à época da autoria do trabalho. Esse procedimento, que difere do adotado por Vergara e Carvalho Jr. (1995), foi adotado a fim de que se pudesse alocar precisamente o total dos 417 trabalhos a cada autor e a cada instituição, evitando, dessa maneira, a contagem dupla.

A categorização (ou codificação) de cada artigo nesses quatro grupos de variáveis foi feita por três pesquisadores independentes (sendo somente um deles um dos autores). Para evitar desvios excessivos de classificação em função da óbvia subjetividade do trabalho de codificação, a coleta e inserção de informações no banco de dados teve uma re-conferência para todas as variáveis, excetuando-se as variáveis "metodologia" e "referências bibliográficas" (não discutida neste artigo) que foram re-codificadas duas vezes.

\section{RESULTADOS}

A seguir apresentaremos os resultados obtidos na classificação e análise dos periódicos já citados em conjunto com os artigos do Enanpad. Sempre que os dados dessas duas sub-populações (periódicos e Enanpad) forem significativamente diferentes, a tabulação e análise dos dois grupos serão segregadas, para facilitar a leitura e entendimento. Os balanços críticos feitos nos últimos anos têm evitado, em geral, combinar o levantamento e análise de trabalhos publicados no Enanpad e nos periódicos. As razões para isso parecem evidentes: primeiro, o volume de trabalhos em qualquer área do Enanpad é maior do que na soma dos periódicos em qualquer período: no caso de RH, o total de artigos em publicados em periódicos (127) é menor do que a metade dos trabalhos apresentados no Enanpad (290); segundo, em função do nível de exigência nesse tipo de evento e das limitações de espaço editorial, os critérios de aprovação para publicação nos periódicos são mais seletivos e rigorosos do que os do Enanpad, assim, combinar sem maior problematização e cuidado os dois conjuntos de dados poderia significar uma distorção importante das conclusões. Por outro lado, ignorar um grupo ou o outro tem implicado em que muitos desses balanços críticos não abranjam a maior parte da produção de suas áreas, privilegiando periódicos ou congressos. Por esse motivo, adotamos aqui a opção de abranger todos os trabalhos das duas bases no presente estudo, porém segregando-os sempre que necessário para efeito de tabulação e análise.

A apresentação dos resultados e de sua análise irá seguir a ordem das variáveis em análise descrita na seção de metodologia: primeiro discutiremos a evolução dos trabalhos de RH em relação ao total de publicações na área, depois nos concentraremos na análise, para os trabalhos classificados como de recursos humanos, da temática, da base epistemológica, do perfil metodológico e da demografia de autoria.

\section{A produção em $\mathrm{RH}$ em relação ao total de produção da área}

No período analisado (1991 a 2000), a produção científica em administração cresceu significativamente (ver Figura 1): o aumento percentual foi de 106\% (de 246 trabalhos em 1991 para 506 trabalhos em 2000), se considerado o número total de trabalhos para o período. Se vistos apenas os artigos em periódicos, o crescimento foi de $46,4 \%$ (causado principalmente - porém não somente - pela inclusão da RAC no plantel de periódicos no meio do período); já no Enanpad, o aumento foi de $144,3 \%$.

No mesmo período, os dados mostram (ver Figuras 2 e 3) que a área de RH aumentou não apenas em volume, acompanhando o crescimento da área como um todo, mas também houve um ligeiro aumento da representatividade em relação a outras áreas: passa-se de 28 trabalhos em 1991 (ou 11,4\% do total de trabalhos na área) para 72 em 2000 (ou 14,2\% do total). Podem ajudar a explicar esse crescimento: a tendência internacional de crescimento do discurso de gestão de pessoas associada à competitividade empresarial (Mohrman, Galbraith, Lawler III (1998); Ulrich (1998), a onda de transformações na praxis de gestão de pessoas no Brasil nessa década, bem como a intensificação do uso da área de RH como meio de veiculação de pesquisa científica pelos psicólogos organizacionais.

A evolução ano a ano (ver Figura 2) dos trabalhos de RH mostra uma grande variabilidade no número de artigos publicados nos periódicos: a RAUSP, por exemplo, publicou treze artigos de RH em 1992, mas apenas um 
em 1999; já a RAP publicou cinco em 1998, e nenhum no ano anterior. A distribuição de artigos de RH entre os periódicos também é bastante variável, observa-se que a RAUSP apresenta a maior porcentagem de artigos em RH em relação ao total de revistas para o período todo, $42 \%$. A RAC, apesar de ter começado a ser publicada somente em 1997, tem percentuais expressivos em 1999 (44\%) e em 2000 (47\%). Caso essa tendência apresentada pela RAC nos dois últimos anos analisados continue após o período, teremos mais contribuições de diferentes linhas editoriais, o que pode ser benéfico para área como um todo, uma vez que haverá uma distribuição menos concentrada da publicação. Por outro lado, a ainda existente concentração em poucas revistas reforça a importância de se analisar a produção acadêmica em RH também a partir dos anais do Enanpad. O percentual do total dos artigos de RH no Enanpad em relação ao total dos artigos no evento (12\%) é semelhante à proporção análoga nas revistas (11\%), o que mostra que embora os critérios de escolha para publicação nos periódicos ou apresentação no encontro sejam diferentes, a representatividade da área de $\mathrm{RH}$ em relação ao total de trabalhos para o período é virtualmente idêntica.

\section{A temática da produção científica em RH}

A análise temática dos artigos (ver Figura 4) na amostra evidencia que a maior parte dos trabalhos apresentados tratou do comportamento organizacional (40\%), seguido de políticas da área (34\%) e funções de RH (21\%). É curioso observar que, no início do período, a área estava focada nas funções de RH (mais da metade dos trabalhos publicados em 1991), mas essa proporção decresce ao longo dos anos, cedendo espaço para políticas - que aparecem mais significativamente a partir de 1992, quando surgem os estudos teóricos sobre a "Administração Estratégica de RH" e os tipos de políticas e modelos que precisariam ser implementados - e para comportamento organizacional. O declínio da temática das funções pode ser explicado também pela crescente informatização e terceirização de RH nos últimos anos, o que gera um interesse maior por como implantar as políticas que dizem respeito às funções e menor pelas formas de operacionalizá-las. A análise de cada periódico demonstra que a RAUSP publicou mais sobre políticas (49\%), enquanto na RAC predominam artigos sobre comportamento (53\%), já na RAP e RAE, políticas e comportamento apresentam proporções semelhantes.

Figura 1 - Número total de artigos publicados em todas as áreas no período

\begin{tabular}{|c|c|c|c|c|c|c|c|c|c|c|c|c|c|}
\hline & 1991 & 1992 & 1993 & 1994 & 1995 & 1996 & 1997 & 1998 & 1999 & 2000 & TOTAL & $\begin{array}{c}\% \\
\text { REVISTAS }\end{array}$ & $\begin{array}{c}\% \\
\text { TOTAL }\end{array}$ \\
\hline RAUSP & 45 & 39 & 45 & 37 & 34 & 41 & 38 & 40 & 34 & 40 & 393 & $\mathbf{3 3} \%$ & $11 \%$ \\
\hline RAC & 0 & 0 & 0 & 0 & 0 & 0 & 19 & 23 & 22 & 15 & 79 & $7 \%$ & $2 \%$ \\
\hline RAP & 34 & 43 & 38 & 45 & 52 & 48 & 47 & 56 & 44 & 52 & 459 & $39 \%$ & $13 \%$ \\
\hline RAE & 18 & 23 & 23 & 19 & 22 & 25 & 29 & 27 & 33 & 35 & 254 & $21 \%$ & $7 \%$ \\
\hline Total Revistas & 97 & 105 & 106 & 101 & 108 & 114 & 133 & 146 & 133 & 142 & 1185 & $100 \%$ & $34 \%$ \\
\hline Enanpad & 149 & 143 & 190 & 215 & 212 & 278 & 243 & 250 & 280 & 364 & 2324 & & $66 \%$ \\
\hline Total Geral & 246 & 248 & 296 & 316 & 320 & 392 & 376 & 396 & 413 & 506 & 3509 & & $100 \%$ \\
\hline
\end{tabular}

Figura 2 - Total de artigos em RH no período

\begin{tabular}{|c|c|c|c|c|c|c|c|c|c|c|c|c|c|}
\hline & 1991 & 1992 & 1993 & 1994 & 1995 & 1996 & 1997 & 1998 & 1999 & 2000 & TOTAL & $\begin{array}{c}\% \\
\text { REVISTAS }\end{array}$ & $\begin{array}{c}\% \\
\text { TOTAL }\end{array}$ \\
\hline RAUSP & 4 & 13 & 1 & 3 & 7 & 9 & 7 & 5 & 1 & 3 & 53 & $42 \%$ & $13 \%$ \\
\hline RAC & 0 & 0 & 0 & 0 & 0 & 0 & 3 & 0 & 4 & 8 & 15 & $12 \%$ & $4 \%$ \\
\hline RAP & 2 & 2 & 4 & 3 & 1 & 3 & 0 & 5 & 3 & 3 & 26 & $20 \%$ & $6 \%$ \\
\hline RAE & 2 & 3 & 5 & 8 & 2 & 3 & 3 & 3 & 1 & 3 & 33 & $26 \%$ & $8 \%$ \\
\hline Total Revistas & 8 & 18 & 10 & 14 & 10 & 15 & 13 & 13 & 9 & 17 & 127 & $100 \%$ & $30 \%$ \\
\hline Enanpad & 20 & 17 & 26 & 25 & 22 & 33 & 27 & 30 & 35 & 55 & 290 & & $70 \%$ \\
\hline Total Geral & 28 & 35 & 36 & 39 & 32 & 48 & 40 & 43 & 44 & 72 & 417 & & $100 \%$ \\
\hline
\end{tabular}


Figura 3 - Proporção entre número de artigos em RH e total de artigos publicados

Evolução de RH vs. Total

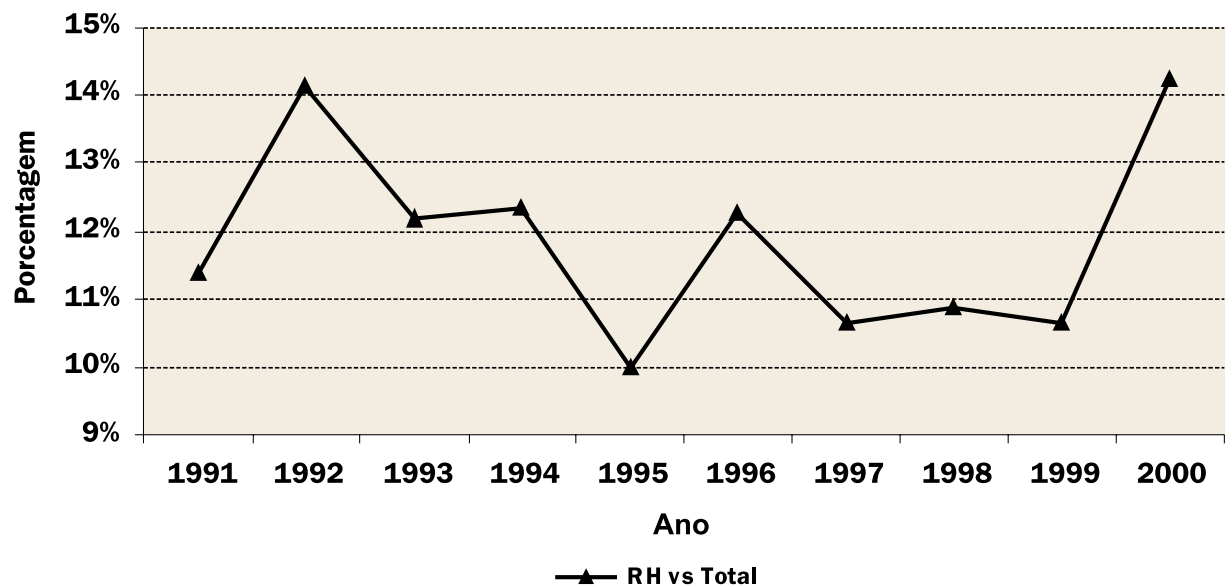

tais seriam necessários para se conseguir que as pessoas trabalhem da maneira desejada. Um outro argumento é que esse aumento proporcional surgiu em função de que psicólogos organizacionais e outros cientistas sociais "redescobriram" nessa área um veículo fértil e receptivo para apresentação e publicação de suas pesquisas. Este segundo argumento, mais político em natureza e circulado pelos corredores da área em recentes Enanpads, sugeriria que $\mathrm{RH}$ teria se tornado uma área de conhecimento com fronteiras historicamente contestadas: de fato, o crescimento dos trabalhos sobre comportamento culminou com uma mudança na área de RH do Enanpad, e com a criação de uma área específica para Comportamento Organizacional a partir do encontro de 2001. A separação dessa grossa - e em geral de ótima qualidade - fatia da produção sem dúvida será sentida pela área, tanto na quantidade e qualidade de trabalhos aceitos quanto no decorrente questionamento e na potencial crise de identidade da área, que poderá ocorrer num futuro próximo.

Uma análise mais detalhada dos sub-temas contidos nesses quatro temas básicos (ver Figura 5) mostra que a distribuição temática reflete o discurso hegemônico do

Figura 4 - Evolução dos temas pesquisados

Evolução dos temas pesquisados

\begin{tabular}{|l|c|c|c|c|}
\hline & POLÍTICAS & FUNÇÕES & COMPORTAMENTO & OUTROS \\
\hline RAUSP & $49 \%$ & $21 \%$ & $25 \%$ & $6 \%$ \\
\hline RAC & $33 \%$ & $13 \%$ & $53 \%$ & $0 \%$ \\
\hline RAP & $35 \%$ & $27 \%$ & $35 \%$ & $4 \%$ \\
\hline RAE & $45 \%$ & $9 \%$ & $42 \%$ & $3 \%$ \\
\hline Enanpad & $30 \%$ & $22 \%$ & $42 \%$ & $6 \%$ \\
\hline
\end{tabular}

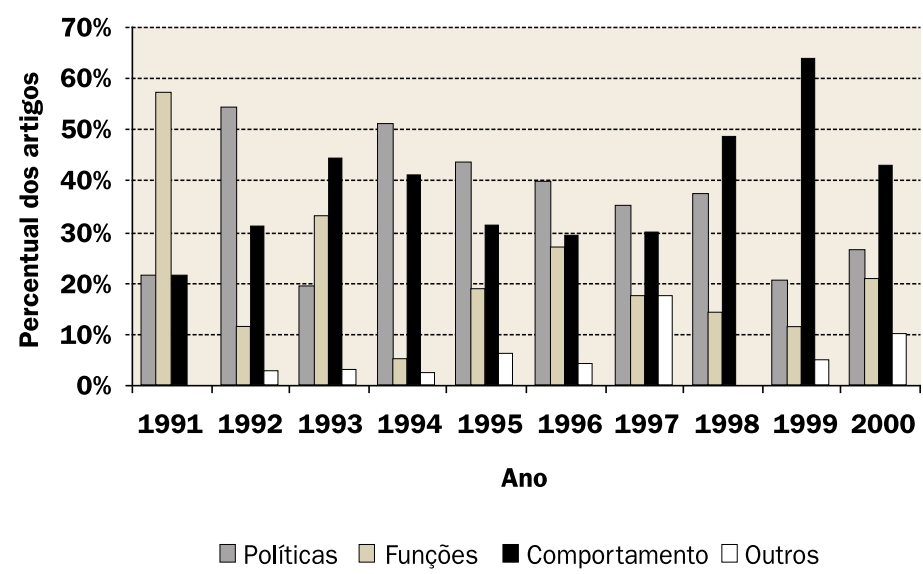


período, que apregoava a promoção de grandes mudanças na gestão de pessoas para acompanhar as transformações das organizações em busca de competitividade (Ulrich, 1997), especialmente a partir de 1990. O maior interesse por temas relacionados às políticas de $\mathrm{RH}$, bem como a ênfase em aspectos comportamentais, parece ressaltar a importância de se fazer essas mudanças e tratar dos problemas a elas associados.

\section{A base epistemológica da produção científica em RH}

Os dados revelam que a produção científica de Recursos Humanos no Brasil é essencialmente funciona- lista (ver Figura 6). Esse tipo de predominância já foi encontrado nos balanços feitos em outras áreas (por exemplo: Machado-da-Silva, Cunha e Amboni, 1990, e Vieira, 1999), no entanto, se comparado a outras áreas ditas "menos exatas", a hegemonia funcionalista em RH é ainda maior, revelando menor diversidade epistemológica do que seria salutar para um país e uma área com tantas contradições e complexidades (Fleury e Fischer, 1992).

Pode-se dizer, como atenuante, que a análise da evolução ano-a-ano mostra um pequeno aumento de trabalhos que utilizam a abordagem interpretacionista nos últimos anos do período investigado. Os trabalhos que

Figura 5 - Subtemas e conteúdos mais freqüentes por grupos temáticos

\begin{tabular}{|c|c|c|c|}
\hline COMPORTAMENTO & FUNÇÕES & POLÍTICAS & OUTROS \\
\hline $\begin{array}{l}\text { - Comprometimento } \\
\text { - Stress } \\
\text { - Aprendizagem } \\
\text { - Gênero } \\
\text { - Saúde } \\
\text { - Papel dos dirigentes/liderança } \\
\text { - Perfil gestores/gestor RH } \\
\text { - Motivação } \\
\text { - Impactos das mudanças na } \\
\text { forma de organização do tra- } \\
\text { balho } \\
\text { - Satisfação no trabalho } \\
\text { - Criatividade } \\
\text { - Relações de poder }\end{array}$ & $\begin{array}{l}\text { - Avaliação de desempenho } \\
\text { - Mudança nas funções } \\
\text { - Treinamento } \\
\text { - Carreira } \\
\text { - Remuneração } \\
\text { - Cargos e salários } \\
\text { - Gestores } \\
\text { - Participação nos lucros } \\
\text { - Qualificação } \\
\text { - Recrutamento e seleção }\end{array}$ & $\begin{array}{l}\text { - Qualidade de Vida no Trabalho } \\
\text { - Modelos de RH } \\
\text { - Gestão por competências } \\
\text { - Gestão participativa } \\
\text { - Cultura } \\
\text { - Diversidade cultural } \\
\text { - Estilos de gestão } \\
\text { - Programas de qualidade } \\
\text { - Relações de trabalho } \\
\text { - Qualificação } \\
\text { - Mudanças em RH } \\
\text { - Mudanças na organização } \\
\text { do trabalho }\end{array}$ & $\begin{array}{l}\text { - Universidades corporativas } \\
\text { - Empresa familiar } \\
\text { - Formação do administrador } \\
\text { - Pesquisa em RH } \\
\text { - Política educacional }\end{array}$ \\
\hline
\end{tabular}

Figura 6 - Base epistemológica dos trabalhos em RH

Base epistemológica

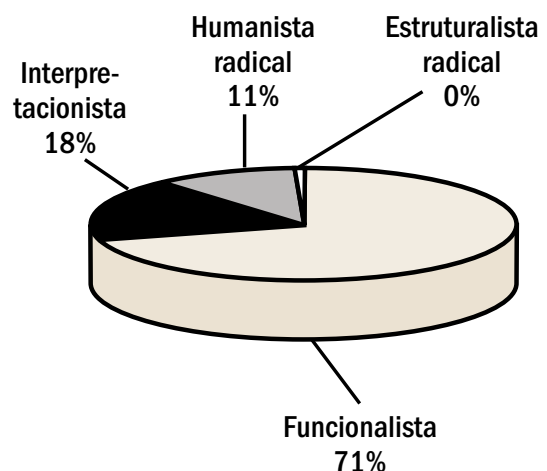

$71 \%$
Evolução da base epistemológica

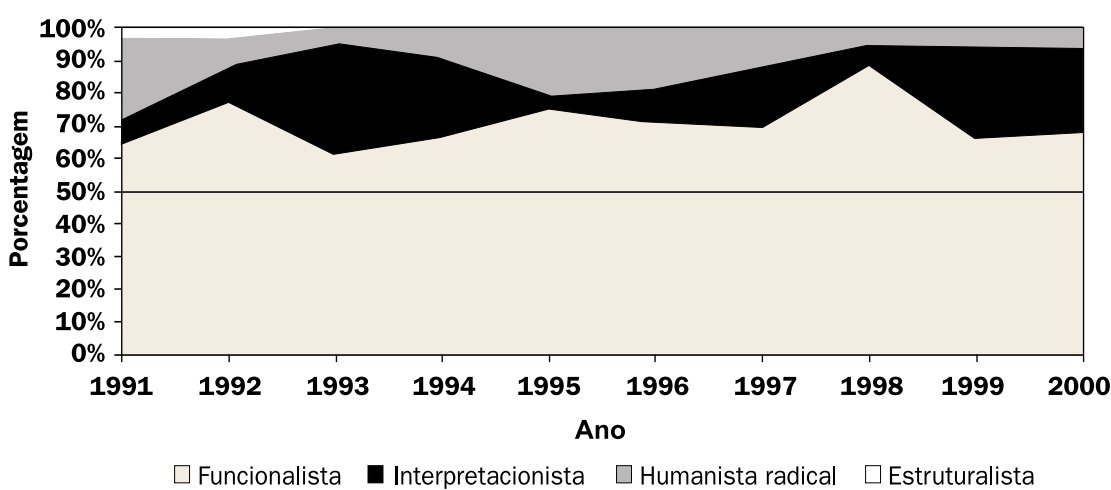


utilizam esse tipo de abordagem são, em geral, estudos comportamentais, que procuram investigar relações e impactos ocasionados por intervenções introduzidas nas organizações por meio da opinião das pessoas e da sua interpretação dos eventos. Se essa tendência persistir, esse tipo de trabalho será, provavelmente, mais característico da recém-criada área de Comportamento Organizacional do que propriamente da área de $\mathrm{RH}$.

O predomínio funcionalista ocorre em praticamente todos os veículos analisados, embora existam extremos. A RAUSP, por exemplo, tem uma predominância marcante de trabalhos funcionalistas (77\%), a passo que a RAC tem uma distribuição mais eqüitativa entre as abordagens funcionalista (47\%) e interpretacionista (53\%). Já RAE e RAP tiveram maior receptividade a uma discussão mais crítica, apresentando maiores números de trabalhos com abordagem humanista radical (24 e 27\%, respectivamente).

\section{0 perfil metodológico da produção científica em $\mathbf{R H}$}

Vimos na seção anterior que a produção científica em RH no período tem uma forte predominância funcionalista e uma falta de diversidade epistemológica preocupante. Essa falta de diversidade poderia ser justificável se a produção de RH tivesse, no Brasil, uma forte orientação positivista e empiricista - como a norte-americana, por exemplo -, que poderia compensar com seu rigor e cientificismo esse predomínio - o que, aliás, seria uma compensação questionável. Como veremos nesta seção, não é o caso: a maior parte dos trabalhos analisados faz apenas sistematizações e revisões de conceitos, modelos e teorias já existentes, ou, dentre os trabalhos com base empírica, predominam os estudos de caso único, de natureza meramente explanatória e descritiva, e os estudos tipo "survey", ambos com limitada pre-

\section{Figura 7 - Abordagem metodológica}

\section{Abordagem metodológica - Revistas}

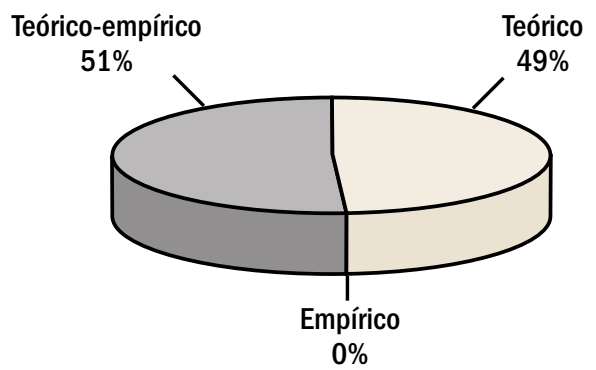

tensão de contribuição científica.

De forma geral, como mostra a Figura 7, os artigos teóricos e teórico-empíricos são ampla maioria dos trabalhos na amostra, sendo os artigos empíricos praticamente inexistentes. Algumas diferenças nessas proporções podem ser encontradas em relação à produção dos periódicos e do Enanpad. Em primeiro lugar, o total dos artigos dos periódicos mostra uma equivalência entre os trabalhos teóricos (49\%) e empíricos (51\%). No entanto, cada periódico pode apresentar diferenças nos tipos de trabalhos publicados: predominam na RAUSP os artigos teórico-empíricos, enquanto na RAP e RAE, a preferência parece ser por artigos de natureza teórica. Quanto à produção apresentada no Enanpad, verificase uma predominância expressiva de artigos teóricoempíricos. A análise da evolução ano-a-ano de todas as publicações (dados analisados, mas não mostrados aqui) mostra uma elevação dos trabalhos teóricos em três anos: 1993, 1994 e 1998. Não há um padrão definido que explique esse aumento - foram anos em que RAP e RAE publicaram mais artigos e essas revistas parecem privilegiar artigos teóricos. Em relação aos trabalhos do Enanpad, a predominância dos artigos teórico-empíricos se mantém ao longo dos anos.

O segundo grupo mais significativo, atrás dos teórico-empíricos, é o de trabalhos essencialmente teóricos. A presença significativa desse tipo de artigo poderia indicar uma área fortemente orientada a produção de teoria e novos conceitos, no entanto, a análise detalhada mostra o contrário: a maior parte desses artigos não têm características ambiciosas, limitando-se em geral - com honrosas exceções - a fazer sistematizações e revisões de conceitos, modelos e teorias já existentes. Do total de artigos teóricos, $61 \%$ faz apenas revisão e sistematização de teoria existente, $37 \%$ apresenta conceitos e apenas 2\% faz tentativa de construção de teoria. Essas

\section{Abordagem metodológica - ENANPAD}

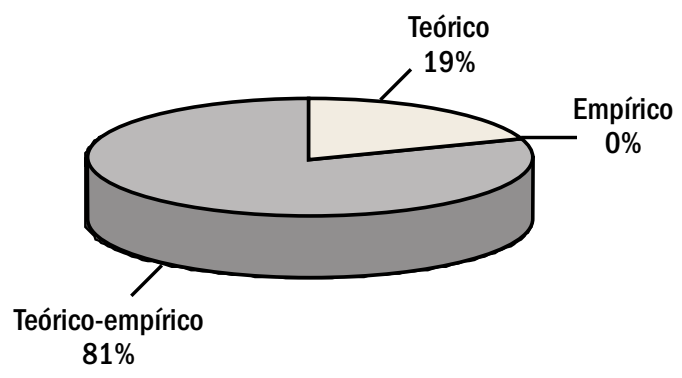


proporções se mantêm semelhantes para cada revista no período, à exceção da RAC (amostra muito pequena). O mesmo tipo de distribuição vale para os trabalhos apresentados no Enanpad, com uma ligeira elevação dos artigos que propõem um conceito - $42 \%$ versus 35\% para o total das revistas.

Mas o grupo mais representativo foi, claramente, o de trabalhos teórico-empíricos. Para retratar melhor a produção com alguma base empírica, os trabalhos empíricos ou teórico-empíricos foram classificados em (ver Figura 8): qualitativos, quantitativos ou mistos (qualitativos / quantitativos). Ao analisar essa divisão, fica evidente que há na área uma predominância, dentre aqueles artigos com alguma base empírica, de trabalhos qualitativos e com baixa pretensão ou sofisticação metodológica.

Analisando essa distribuição por periódico, há bastante variância: a RAE e a RAUSP não apresentaram nenhum trabalho que utilizasse os dois métodos de pesquisa (qualitativo / quantitativo); a RAC tem a mesma proporção de trabalhos qualitativos e mistos (43\%) e a RAP tem mais artigos qualitativo / quantitativos (71\%). Para os trabalhos apresentados no Enanpad, predomina também o estudo qualitativo (67\%); artigos que utilizam metodologia qualitativa e quantitativa representam $27 \%$ do total e os quantitativos são apenas $6 \%$. Ainda que a existência do trabalho qualitativo seja desejável, é preocupante sua grande hegemonia na área, o que po- deria indicar uma pequena preocupação na busca de confirmação de resultados ao longo do período, embora se observe, na evolução ano-a-ano (dados analisados, mas não mostrados neste artigo), uma aparente tendência de queda na proporção dos trabalhos qualitativos e um aumento proporcional em artigos que adotam técnicas mistas.

Pela significância de sua proporção, é preciso entender melhor que tipo de trabalho qualitativo está sendo produzido na área. Os resultados mostram (ver Figura 9) um retrato preocupante, ao revelar que, na sua maioria, os trabalhos qualitativos da área restringem-se a estudos de caso, limitados em termos de pretensão - a maioria é de natureza descritiva ou explanatória (ilustrativa), sem maior anseio de construção indutiva de teoria (o que seria possível em outro tipo de estudo de caso, como discutido adiante).

De fato, à exceção de poucos períodos - 1992, 1997 e 1998 no caso das revistas, ou ainda um especial da RAUSP em 1992 com diversas metodologias -, o estudo de caso corresponde à maioria dos trabalhos qualitativos na amostra. Essa predominância não seria um problema se a área fosse povoada por estudos de múltiplas influências, mais subjetivistas e não funcionalistas, no entanto, na verdade, como vimos anteriormente, a maioria é predominantemente funcionalista, usa uma abordagem teórico-empírica de natureza qualitativa, e representa em geral estudos de caso, que comumente redu-

Figura 8 - Classificação dos trabalhos teórico-empíricos e empíricos

\section{Classificação}

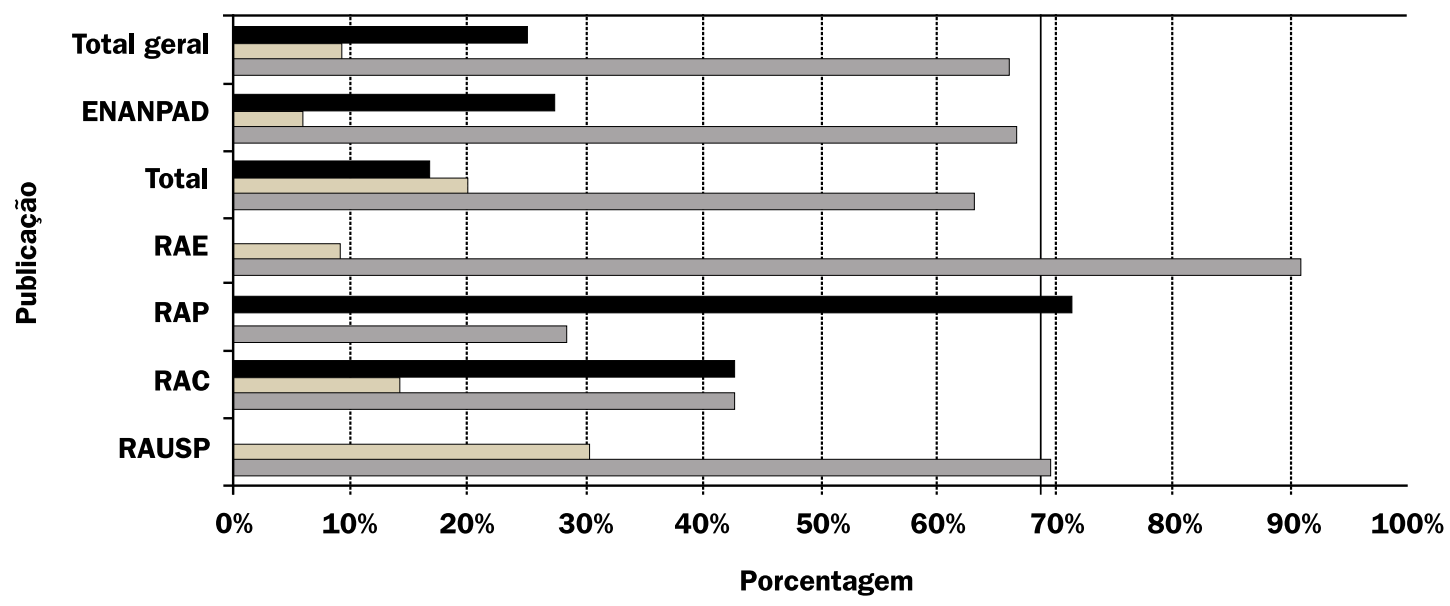

$\square$ Quali $\square$ Quanti $\quad$ Quali / Quanti 
zem o estudo à análise de um único evento ou situação especial. Dentro da tradição funcionalista na qual se encaixa essa maioria de trabalhos, essa alta proporção é, sim, preocupante, em especial porque para constituir contribuição científica significativa, a tradição funcionalista exige o cumprimento de rigorosos critérios, conforme alertam Eisenhardt (1989) e Yin (1998). Ao classificar os estudos de caso seguindo esses critérios, constata-se que (ver Figura 10) predominam na amostra os estudos de caso único e de natureza explanatória (ilustrativa) e descritiva, justamente aqueles que autores como os citados acima alertam para o baixo nível de contribuição científica. Críticos desse tipo de abordagem de caso, esses autores mostram que trabalhos meramente descritivos ou ilustrativos apenas reforçam (muitas vezes apenas proverbialmente) teoria já consolidada, raramente trazendo alguma contribuição. Para eles, estudos de casos tornam-se importante ferramenta científica quando têm natureza exploratória, em que, a partir dos dados e da construção indutiva de teoria, propõe-se conhecimento novo à área. Em última análise, isso significaria que boa parte da produção da área vem se limitando a estudar contextos específicos e que, portanto, os resultados encontrados dificilmente poderão ter algum grau mais elevado de generalização.

Dentre os veículos estudados, a RAE constitui uma exceção, pois apresenta maior número de artigos com estudos de casos múltiplos e também maior número de casos de natureza exploratória (que visam construir teoria). O número de casos múltiplos apresentados no Enanpad é menor, em geral, do que o publicado nas revistas.

Já a análise dos artigos quantitativos e mistos (dados analisados, mas não apresentados neste artigo) mostra semelhante nível de despretensão da pesquisa na amostra estudada.

No caso de trabalhos quantitativos, todos os artigos desse tipo publicados nas revistas são survey, sendo este tipo de pesquisa também maioria entre os trabalhos quantitativos apresentados no Enanpad. Novamente observa-se a ausência de tentativa de comparação entre dados qualitativos e quantitativos nesse tipo de trabalho. Pesquisas survey, no entanto, foram mais encontradas em trabalhos que estudavam as funções e políticas de RH, nos quais se buscava estabelecer padrões ou critérios para melhor estruturar a área por meio de levantamentos - em geral, questionários enviados por correio - que cobrissem grande número de organizações. A predominância desse tipo de estudo - "survey" - entre os trabalhos quantitativos também é uma característica preocupante do perfil da área uma vez que se sabe que estudos desse tipo tipicamente têm dificuldade em apresentar avaliações de natureza qualitativa - o que funciona e que não funciona, por exemplo - e, nesse sentido, tendem a servir mais como referencial - ou "retrato", como a presente investigação - do que está sendo feito do que como critério para recomendações de utilização futura para outras empresas, ou para efetiva construção de teoria nova.

Figura 9 - Classificação dos trabalhos qualitativos

Classificação dos trabalhos qualitativos

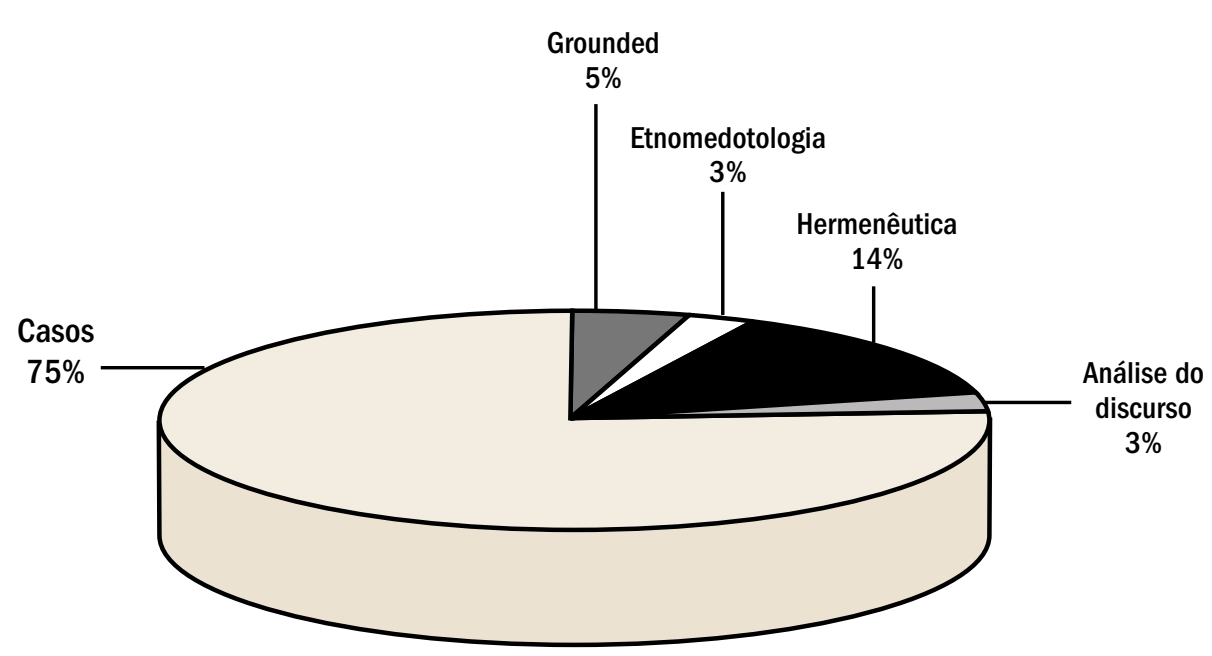


Já no caso dos artigos mistos (de natureza qualitativa / quantitativa), observa-se também a predominância de estudos de caso com amostras únicas e de natureza meramente explanatória ou descritiva. Utiliza-se, de maneira geral, um questionário para um grande número de pessoas; eventualmente, são conduzidas também algumas entrevistas para aprofundar tópicos que surgem a partir dos questionários. Embora se possa observar e aplaudir o crescimento dos trabalhos de natureza qualitativo/quantitativa no período, e um maior esforço de comparação e análise de dados nesses trabalhos, permanece o problema do estudo da amostra única e a dificuldade de generalização e utilização adequada dos resultados por outras organizações.

Ou seja, em essência, a análise do perfil metodológico da produção em RH no período revela um quadro grave e preocupante: uma produção de natureza tipicamente funcionalista, em que predominam estudos teórico-empíricos, mas que são, em geral, estudos de caso de amostra única com pretensão de apenas descrever ou detalhar um evento ou uma situação em uma organização, deixando ao campo pouco conhecimento novo e discutível resíduo de contribuição científica.

\section{Demografia de autoria e origem dos autores e instituições}

Em relação à demografia de autoria, os dados evidenciam uma produção extremamente restrita a poucas instituições e, no caso do Enanpad, a um punhado de pes- quisadores, o que revela uma área de baixa diversidade e carente de uma maior inclusão temática, epistemológica, metodológica e de região de origem. Em função das diferenças que surgiram nesses dados entre os periódicos e o Enanpad, no entanto, fez-se necessário separar aqui a análise dos dois tipos de fontes nesta seção.

Quando somados os artigos de todos os periódicos (ver Figura 11), tem-se que a FEA-USP é a instituição que mais publicou no período, 17,7\%; em seguida, contribuem os autores internacionais, com 11,8\%; UNB tem $11,5 \%$ do total dos artigos publicados; FGV-EAESP, 10,7\%; UFRGS, 9,1\%; FGV-RJ, 7,5\%; artigos de profissionais de empresas, 5,3\%; UFMG, 4,8\%; UFSC, 3,6\% e UFBA, 2,4\%. Essas 10 fontes de autoria contribuem com $84 \%$ de toda a publicação dos periódicos, o que reforça a idéia de concentração em apenas algumas instituições de ensino brasileiras.

Algo nesses dados relativos à publicação nos periódicos salta aos olhos; parece claro que os periódicos publicam expressivamente os artigos dos professores das próprias instituições que os patrocinam. Na RAUSP, observa-se uma concentração de artigos provindos de três instituições: 30\% da FEA-USP, 16\% da UNB e 13\% da UFRGS; na RAP, 33\% são da FGV-RJ, $15 \%$ são artigos escritos por profissionais de empresas e $11 \%$ do artigos vêm da UNB. Na RAE, a maior parte dos artigos são de autores de instituições estrangeiras, 33\%, 29\% são artigos de professores da

Figura 10 - Classificação dos artigos qualitativos - Estudos de caso

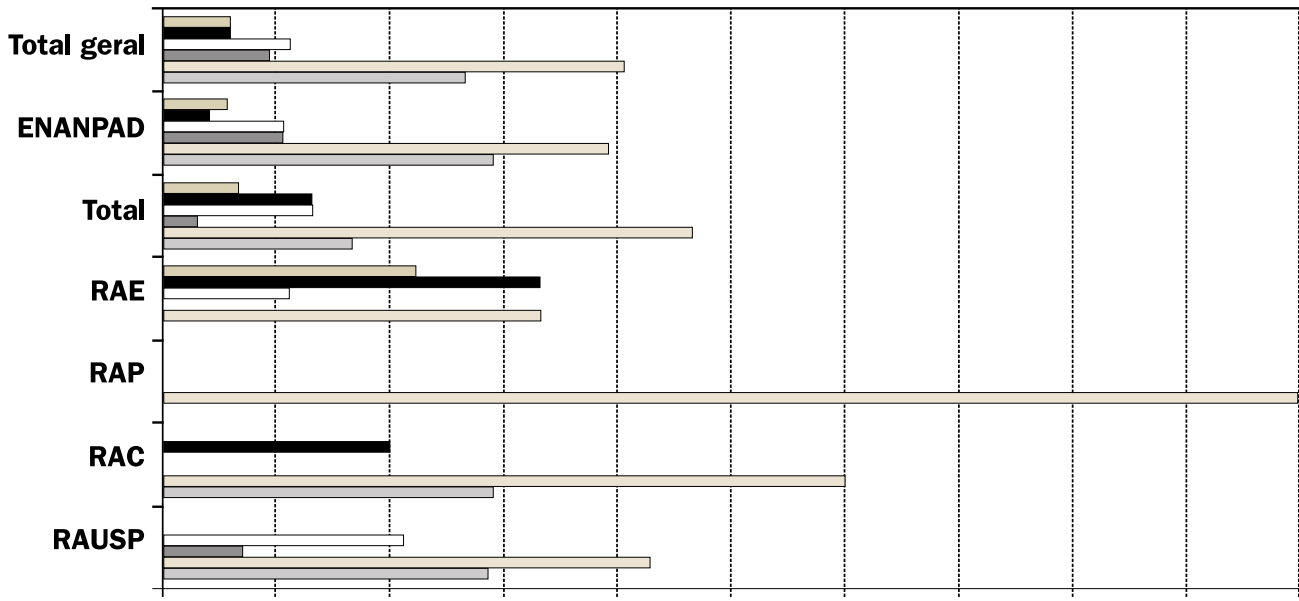

$\square$ Único - explanatório

$\square$ Múltiplo - explanatório $\square$ Único - descritivo

Múltiplo - descritivo
Único - exploratório

Múltiplo - exploratório 
própria FGV-EAESP e $12 \%$ foram escritos por professores da FEA-USP. A honrosa exceção é a RAC, que apresenta uma distribuição bastante pulverizada de instituições e autores.

Quanto à produção veiculada no Enanpad, observase igualmente um elevado grau de concentração de instituições de origem, embora não sejam exatamente as mesmas. As 10 instituições que mais trabalhos apresentam na área de RH do congresso respondem por $76 \%$ do total dos trabalhos apresentados (ver Figura 12), as 7 principais respondem por $65 \%$ da produção, e o que é mais inquietante, $50 \%$ de todos os trabalhos apresentados provem de apenas três programas - UFMG, FEA e UFRGS. É curioso notar que a instituição com maior contribuição no Enanpad - UFMG - não tem publicado de maneira tão expressiva nos periódicos.

Quando é analisada não apenas a instituição de origem, mas a autoria individualmente, a concentração também fica evidenciada, principalmente na produção veiculada no Enanpad, já no caso dos periódicos, embora haja concentração da instituição de origem, a análise detalhada revela que a contribuição individual oscila saudavelmente - muito de ano para ano, não havendo constância (de autor) em termos do número de trabalhos publicados ou mesmo na proporção que representam do total para cada ano.

Já no Enanpad, os mesmos autores tenderam a consistentemente dominar a maior parte da produção no

Figura 11 - Distribuição de instituição de origem dos autores - Periódicos

\begin{tabular}{|c|c|c|c|c|c|c|c|c|c|c|c|c|}
\hline $\begin{array}{c}\text { INSTITUI- } \\
\text { ÇÕES } \\
(10+)\end{array}$ & $\begin{array}{l}\text { FEA- } \\
\text { USP }\end{array}$ & $\begin{array}{l}\text { INTER- } \\
\text { NAC. }\end{array}$ & UNB & $\begin{array}{l}\text { FGV- } \\
\text { EAESP }\end{array}$ & UFRGS & $\begin{array}{l}\text { FGV- } \\
\text { RJ }\end{array}$ & $\begin{array}{c}\text { EMPRE- } \\
\text { SAS }\end{array}$ & UFMG & UFSC & UFBA & $\begin{array}{c}\text { TOTAL } \\
10+\end{array}$ & $\begin{array}{c}\% \text { DO } \\
\text { TOTAL } \\
\text { ARTIGOS }\end{array}$ \\
\hline & $\%$ & $\%$ & $\%$ & $\%$ & $\%$ & $\%$ & $\%$ & $\%$ & $\%$ & $\%$ & $n$ & $\%$ \\
\hline 1991 & 31 & 23 & 0 & 0 & 0 & 31 & 0 & 15 & 0 & 0 & 7 & 81 \\
\hline 1992 & 38 & 19 & 0 & 6 & 13 & 6 & 19 & 0 & 0 & 0 & 16 & 89 \\
\hline 1993 & 25 & 31 & 13 & 13 & 0 & 0 & 6 & 0 & 0 & 13 & 8 & 80 \\
\hline 1994 & 13 & 13 & 0 & 31 & 13 & 19 & 0 & 13 & 0 & 0 & 8 & 57 \\
\hline 1995 & 30 & 0 & 10 & 10 & 30 & 10 & 0 & 10 & 0 & 0 & 10 & 100 \\
\hline 1996 & 7 & 15 & 39 & 10 & 15 & 15 & 0 & 0 & 0 & 0 & 14 & 91 \\
\hline 1997 & 14 & 21 & 0 & 27 & 17 & 0 & 0 & 0 & 13 & 8 & 12 & 93 \\
\hline 1998 & 22 & 9 & 28 & 22 & 0 & 9 & 3 & 0 & 9 & 0 & 12 & 89 \\
\hline 1999 & 0 & 4 & 28 & 0 & 15 & 15 & 24 & 15 & 0 & 0 & 7 & 76 \\
\hline 2000 & 23 & 9 & 16 & 8 & 4 & 0 & 2 & 16 & 16 & 8 & 13 & 76 \\
\hline Total & 18 & 12 & 11 & 11 & 9 & 7 & 5 & 5 & 4 & 2 & 107 & 84 \\
\hline
\end{tabular}

Figura 12 - Distribuição de instituição de origem dos autores - Enanpad

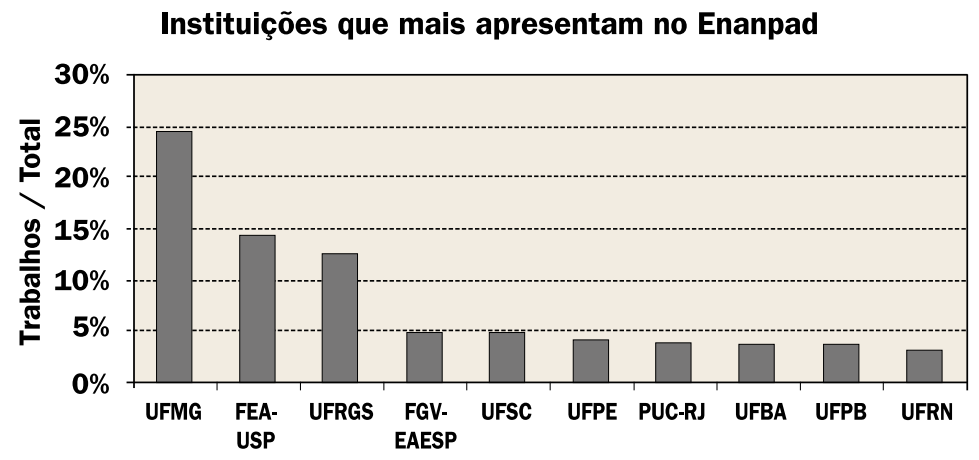


período (ver Figura 13). Os 16 autores com mais trabalhos apresentados têm $20,72 \%$ de toda a produção. Vale lembrar, no entanto, que 13 desses autores provêm de apenas 3 instituições - FEA-USP, UFMG e UFRGS - e que, além desses, outros autores (dessas mesmas instituições) também apresentam e publicam trabalhos, perfazendo $52 \%$ do total dos trabalhos somente desses 3 programas de pós-graduação.

Esses dados reforçam a idéia de que a produção da área está concentrada em alguns programas (com diversos pesquisadores) o que explica, em parte, a concentração em alguns tipos de linhas de pesquisa. Por sua vez, isso poderia ajudar a explicar o direcionamento da área para determinados temas e para uma restrita linha epistemológica e metodológica. Não se pode negar que, se de um lado, esses centros e autores vêm construindo a área e se tornando a referência da produção acadêmica nacional, por outro, seria de se esperar que o desenvolvimento da área de RH como um todo se beneficiaria de uma produção que fosse mais representativa de todas as regiões do país e de diferentes matizes temáticas, epistemológicas e metodológicas. Em outras palavras, os dados da pesquisa revelam que, se a área quiser maior diversidade teórica e científica, é preciso primeiro aumentar a diversidade de origem da produção que aceita e veicula, bem como estimular a produção científica mais rigorosa e de diferentes tradições epistemológicas e metodológicas.

\section{CONCLUSÃO}

Não há dúvidas de que o quadro apresentado nesta pesquisa é revelador mas também preocupante. A pesquisa mostrou que a produção científica em RH na década de 1990, no Brasil, embora tenha aumentado significativamente em volume, guarda um perfil acadêmico de baixa consistência e qualidade: seu escopo temático é contestado pelo recente crescimento e autonomia do campo de comportamento organizacional; a área tem base epistemológica eminentemente funcionalista; sua base metodológica é frágil, predominando estudos de caso tipicamente ilustrativos de teoria consolidada (ou seja, sem maior pretensão de indução ou criação de teoria); e, ainda há baixa diversidade de origem, tendo a maior parte da produção advindo de pouquíssimas instituições, autores e regiões.

O crescimento da produção em RH é louvável e significativo: $106 \%$ no período, com ligeiro aumento de representatividade em relação a outras áreas: de 11,4\% em 1991 para 14,2\% em 2000. Mas esse crescimento é

Figura 13 - Distribuição de autoria dos artigos

\begin{tabular}{|c|c|c|c|c|c|c|}
\hline \multirow[t]{2}{*}{ AUTOR } & \multicolumn{2}{|c|}{ ENANPAD } & \multicolumn{2}{|c|}{ REVISTAS } & \multicolumn{2}{|c|}{ TOTAL } \\
\hline & n & \%TOTAL & n & \% TOTAL & $\mathrm{n}$ & \%TOTAL \\
\hline Fleury, Maria Tereza - FEA/USP & 6,33 & 2,18 & 3,00 & 2,36 & 9,33 & 2,24 \\
\hline Piccinini, Valmiria - UFRGS & 5,08 & 1,75 & 2,00 & 1,57 & 7,08 & 1,70 \\
\hline Melo, Marlene - UFRGS & 6,00 & 2,07 & 1,00 & 0,79 & 7,00 & 1,68 \\
\hline Albuquerque, Lindolfo - FEA/USP & 3,00 & 1,03 & 2,50 & 1,97 & 5,50 & 1,32 \\
\hline Barbosa, Allan - UFMG & 4,50 & 1,55 & 1,00 & 0,79 & 5,50 & 1,32 \\
\hline Eboli, Marisa - FEA/USP & 4,00 & 1,38 & 1,00 & 0,79 & 5,00 & 1,20 \\
\hline Caldas, Miguel - FGV- EAESP & 3,50 & 1,21 & 1,00 & 0,79 & 4,50 & 1,08 \\
\hline Marques, Antonio - UFMG & 4,00 & 1,38 & 0,33 & 0,26 & 4,33 & 1,04 \\
\hline Tomei, Patrícia - PUC-RJ & 2,83 & 0,98 & 1,50 & 1,18 & 4,33 & 1,04 \\
\hline Fischer, Rosa - FEA/USP & 2,00 & 0,69 & 2,00 & 1,57 & 4,00 & 0,96 \\
\hline Moraes, Lucio - UFMG & 4,00 & 1,38 & 0,00 & 0,00 & 4,00 & 0,96 \\
\hline Antunes, Elaine - UFRGS & 3,33 & 1,15 & 0,50 & 0,39 & 3,83 & 0,92 \\
\hline Bastos, Antonio - UFBA & 2,00 & 0,69 & 1,83 & 1,44 & 3,83 & 0,92 \\
\hline Garcia, Fernando - UFMG & 3,50 & 1,21 & 0,00 & 0,00 & 3,50 & 0,84 \\
\hline Lima, Maria - UFMG & 2,50 & 0,86 & 1,00 & 0,79 & 3,50 & 0,84 \\
\hline Siqueira, Moema - UFMG & 3,50 & 1,21 & 0,00 & 0,00 & 3,50 & 0,84 \\
\hline Total & 60,08 & 20,72 & 18,66 & 14,69 & $\mathbf{7 8 , 7 4}$ & 18,88 \\
\hline
\end{tabular}


também preocupante, por não ter sido acompanhando de um crescimento do rigor científico e da qualidade da produção. Esse tipo de inquietude com a consistência e qualidade da área e de nossa produção dá-se em todas as dimensões analisadas.

Por exemplo, do ponto de vista temático é preocupante, pois revela, na verdade, um conflito de fronteira: a produção sobre comportamento organizacional deve estar dentro de RH ou deve ser segregada? Com a separação da área de Comportamento Organizacional a partir do Enanpad de 2001, essa questão começa a ser resolvida de uma forma dramaticamente perigosa para área de RH, uma vez que a maior parte de sua produção (40\%) no período esteve concentrada justamente nessa linha temática, que agora parece começar a perder. Essa separação de parte tão importante do passado recente da área certamente será sentida, e enseja um urgente repensar da área, que terá de encontrar novos centros de preocupação, numa oportunidade de priorizar linhas de pesquisa em âmbito nacional, como outras áreas fizeram recentemente (exemplo da própria Psicologia Organizacional).

A baixa diversidade epistemológica, por sua vez, é preocupante pois, ao escolher uma base eminentemente funcionalista, a área se alinha em escolha com a produção internacional do campo, mas não se posiciona como produtora de conhecimento e teoria de primeira linha no cenário mundial, restando-lhe apenas o papel de coadjuvante e reprodutor do que é produzido e pensado lá fora. Além disso, domesticamente, a baixa diversidade tampouco é salutar para resolver nossos problemas e ajudar a práxis organizacional local, um outro posicionamento possível - uma área com tantas contradições e complexidades precisaria, para ser útil, de grande diversidade e inclusão epistemológica, ontológica e de ampla representatividade regional; carecemos de todas essas dimensões de inclusão no período analisado nesta pesquisa.

A frágil base metodológica da área revelada na pesquisa é talvez a mais evidente e desconfortável de todas as constatações preocupantes observadas, o predomínio de estudos de caso apenas ilustrativos de teoria consolidada, isto é, sem maior pretensão de indução ou criação de teoria, ou ainda de estudos tipo survey, revelam uma contradição com a linha epistemológica escolhida pela área, e reforçam o ciclo pela falta de produção de conhecimento mais significativa e contributiva para a área em termos internacionais. Realmente, se a área pretende ter alguma significância, precisará superar sua histórica limitação em termos de desenho e pretensão metodológica.
Por fim, a baixíssima diversidade de origem é também muito preocupante porque não aponta tendências de superação dos problemas da área: quando mais de $65 \%$ da produção vem de apenas 7 programas de pósgraduação e $19 \%$ de somente 16 autores, reforça-se o ciclo vicioso que restringe a nossa produção científica conhecida àquelas linhas temáticas, às orientações epistemológicas, às limitações metodológicas e às perspectivas de mundo regionais, que tais poucos autores e instituições conseguem construir.

Em tempos do clamor pela inclusão social, pela inclusão digital etc., parece ser tempo da área pensar também em inclusão. De outros temas. De outras bases epistemológicas e metodológicas. De outras regiões e de outros pensadores. Não em vez de, mas além de, aqueles que hoje para ela contribuem. Enfim, é tempo de RH pensar na inclusão de si própria, tanto no cenário de produção científica internacional, quanto no terreno de produção científica de alta qualidade, ou de grande aplicabilidade prática. Ou, quiçá, de ambas.

Para a representatividade, importância e prestígio que RH possui dentro da área de Administração, sem dúvida o quadro apresentado por esta pesquisa não faz justiça ao espírito e às aspirações da área. Por outro lado, a pesquisa mostra importantes vetores de mudança e possibilidades de superação e aprimoramento. Acreditamos que, nesse sentido, o retrato que a pesquisa proporciona é preocupante e grave, sim, mas que sua contribuição é positiva: não existe crescimento se não há auto-consciência e percepção das nossas limitações e dificuldades. Assim, acreditamos que a área de RH precisa urgentemente engajar-se em um debate sério, abrangente e inclusivo sobre o que quer, como quer e até onde quer chegar.

O desafio é imenso, mas não é impossível, e certamente não maior do que a área.

\section{Artigo Convidado. Aprovado em 08/10/2002.}

\section{Notas}

Este artigo foi realizado por meio de duas pesquisas financiadas pelo NPPFGV-EAESP, ao qual os autores só têm a agradecer. Os autores também gostariam de agradecer a (i) Filipe David e Jefferson Kasa, bolsistas do PIBIC/FGV-EAESP, pela ajuda na coleta e codificação dos dados; (ii) aos avaliadores (anônimos) da primeira versão deste artigo no Enanpad, bem 
como à comunidade de RH do evento em 2002, em especial ao ALLAN CLAUDIUS BARBOSA (UFMG), que com suas observações e sugestões viabilizaram significativos aperfeiçoamentos nos procedimentos metodológicos que utilizamos, como a proporcionalidade de autoria, que evitou a dupla contagem da demografia de autoria.

1. A existência de outras publicações acadêmicas de primeira linha no Brasil hoje existentes, como Organizações e Sociedade e REO (Revista de Estudos Organizacionais) não foi desprezada, no entanto, como tais periódicos só chegaram a estágios editoriais mais consolidados no final do período, seus conteúdos não foram incluídos na base de dados sob investigação. Sugerimos fortemente que uma análise focada em período posterior considere a inclusão desses importantes periódicos brasileiros na investigação.

\section{Referências bibliográficas}

Academy of Management Review - AMR. Special Issue on Theory Building. Vol.14, No. 4, 1989

Administrative Science Quarterly - ASQ. Forum on Theory Building. Vol. 40 (Special Issue), 1995

ALVESSON, M. e SKÖLDBERG, K. Reflexive methodology: new vistas for qualitative research. London: Sage Publications, 2000

BAUER, Martin W. e GASKELL, George. Pesquisa Qualitativa com Texto, Imagem e Som. Petrópolis, Ed. Vozes, 2002.

BERTERO, C. O e KEINERT, T. M. M. "A evolução da Análise Organizacional no Brasil (1961-93)". Revista de Administração de Empresas. São Paulo, v. 34, n. 3, maio/junho, 1994. p.81-90.

BERTERO, C.O., CALDAS, M. e WOOD, T. "Produção Científica em Administração de Empresas: Provocações, insinuações e contribuições para um debate local". Revista de Administração Contemporânea, v.3, n.1, jan./ abr.,1999. p.147-178

BIGNETTI, L. P. e PAIVA, E.L. Estudo das citações de autores de estratégia na produção acadêmica brasileira. In: ENCONTRO ANUAL DA ASSOCIAČ̃̃O NACIONAL DOS PROGRAMAS DE PÓS-GRADUAÇÃO EM ADMINISTRAÇÃO, $21^{\circ}$, 1997, Rio das Pedras. Anais... Rio das Pedras: Anpad, 1997. Produção Industrial e Serviços.

BOTELHO, Delane, MACERA, Andrea. Análise metateórica de teses e dissertações da área de marketing apresentadas na FGV-EAESP (1974-1999). In: ENCONTRO ANUAL DA ASSOCIAÇÃO NACIONAL DOS PROGRAMAS DE PÓS-GRADUAÇÃO EM ADMINISTRAÇÃO, 25, 2001, Campinas. Anais... Campinas: Anpad, 2001. Marketing.

BURRELL, G., MORGAN, G., Sociological paradigms and organisational analysis, London: Heinemann, 1979.

CRESWELL, J. Qualitative Inquiry and research design: choosing among five traditions. London: Sage Publications, 1998.

CRESWELL,J.W. Research Design - qualitative, quantitative and mixed methods approaches, $2^{\text {nd }} e d$, London: Sage, 2003.

DEVANA, M., FOMBRUN, C., TICHY, N. M. Strategic Human Resource Management. New York: John Wiley \& Sons, 1984.
DENZIN, Norman K. LINCOLN, Yvonna. Handbook of Qualitative Research, London, Sage, 1994

EISENHARDT, Kathleenn. "Building Theories from Case Study Research.". The Academy of Management Review, v.14, n.4, outubro, 1989. p.532-550.

FLEURY, M. T., FISHER, R.M. Relações de Trabalho e Políticas de Gestão - uma História das Questões Atuais. In: ENCONTRO ANUAL DA ASSOCIAÇÃO NACIONAL DOS PROGRAMAS DE PÓS-GRADUAÇÃO EM ADMINISTRAÇÃO, 16ㅇ, 1992, Canela. Anais...v.8, p.106-120. Canela: Anpad, 1992

FRENCH, W. L. The Personnel Management Process. Boston, $5^{\text {th }}$ ed., Houghton Mifflin, 1982

HOPPEN, N., AUDY, J.L.N., ZANELA, AI.C., CANDOTTI, C.T., SANTOS, A M., SCHEID, R. PERIN, M.G., MECCA, M.S. e PETRINI, M. Sistemas de Informação no Brasil: uma análise dos artigos científicos dos anos 90. In ENCONTRO ANUAL DA ASSOCIAÇÃO NACIONAL DOS PROGRAMAS DE PÓS-GRADUAÇ̃̃O EM ADMINISTRAÇÃO, 22², 1998, Foz do Iguaçu. Anais... Foz do Iguaçu: Anpad, 1998. Administração da Informação.

LEGGE, K., Human Resource Management - Rhetorics and Realities, London MacMillan, 1995.

MACHADO-DA-SILVA, Clóvis L., CUNHA, Vera C., AMBONI, Nério Organizações: o estado da arte da produção acadêmica no Brasil. In: ENCONTRO ANUAL DA ASSOCIAÇÃO NACIONAL DOS PROGRAMAS DE PÓS-GRADUAÇÃO EM ADMINISTRAÇÃO, 14², 1990, Florianópolis Anais... Florianópolis: Anpad, 1990. Organizações. p.11-28.

MARTINS, G. "Abordagens metodológicas em pesquisas na área de Administração" Revista de Administração.São Paulo, v. 32, n.3, julho / setembro, 1997. p. 5-12.

MOHRMAN, Susan, GALBRAITH, Jay, LAWLER III, Edward. Tomorrow's Organization - crafting winning capabilities in a dynamic world. San Francisco: Jossey-Bass Publishers, 1998.

KEINERT, Tânia M. O que é administração pública no Brasil? In: ENCONTRO ANUAL DA ASSOCIAÇÃO NACIONAL DOS PROGRAMAS DE PÓS-GRADUAÇ̃̃O EM ADMINISTRAČ̃̃O, 24으, 2000, Florianópolis. Anais... Florianópolis: Anpad, 2000. Marketing.

PERIN, Marcelo G., SAMPAIO, Cláudio H., FROEMMING, Lurdes M. S., LUCE, Fernando B. A pesquisa survey em artigos de marketing nos Enanpads da década de 90. In: ENCONTRO ANUAL DA ASSOCIAÇÃO NACIONAL DOS PROGRAMAS DE PÓS-GRADUAÇÃO EM ADMINISTRAÇÃO, 24º , 2000, Florianópolis. Anais... Florianópolis: Anpad, 2000.

ROESCH, S., ANTUNES, E. e SILVA, L.V. Tendências da pesquisa em Recursos Humanos e Organizações: uma análise das dissertações de mestrado In: ENCONTRO ANUAL DA ASSOCIAÇÃO NACIONAL DOS PROGRAMAS DE PÓS-GRADUAÇÃO EM ADMINISTRAÇÃO, 21ํ, 1997, Rio das Pedras. Anais... Rio das Pedras: Anpad, 1997.

SATO, Leny. "Processos Organizativos cotidianos e corriqueiros: a leitura da etnometodologia". Psicologia e Sociedade.São Paulo, v.13, n.1. jan/jun 2001.p.129-151.

SIQUEIRA, Moema. O tema Recursos Humanos nas reuniões da ANPAD trajetórias e perspectivas. In: ENCONTRO ANUAL DA ASSOCIAC̄̃O NACIONAL DOS PROGRAMAS DE PÓS-GRADUAÇÃO EM ADMINISTRAÇÃO, 12², 1988, Salvador. Anais... Salvador: Anpad, 1988. 
STOREY, J. "Human Resource Management Today: an Assessment." In: STOREY, J. (Ed.) Human Resource Management - A Critical Text, $2^{\text {nd }}$ ed. London: Thomson Learning, 2001.

STOREY, John. New perspectives on Human Resource Management. London, ITP, 1999.

VERGARA, Sylvia C., CARVALHO JR., Dourival de S. Nacionalidade dos autores referenciados na literatura brasileira sobre organizações. In: ENCONTRO ANUAL DA ASSOCIAÇÃO NACIONAL DOS PROGRAMAS DE PÓS-GRADUAÇÃO EM ADMINISTRAÇÃO, 19o, 1995, João Pessoa. Anais... João Pessoa: Anpad, 1995. Vol. 6. Organizações.

VERGARA, S., PINTO, M. C. S. "Nacionalidade das referências teóricas em análise organizacional: um estudo das nacionalidades dos autores referenciados na literatura brasileira." In: ENCONTRO NACIONAL DE ESTUDOS ORGANIZACIONAIS, 1ㅇ, 2000, Curitiba. Anais...Curitiba, 2000.

VIEIRA, Francisco G. D. Por quem os sinos dobram? Uma análise da publicação científica na área de marketing do Enanpad. In: ENCONTRO ANUAL DA ASSOCIAÇÃO NACIONAL DOS PROGRAMAS DE PÓS-GRADUAÇÃO EM ADMINISTRAÇÃO, 22º, 1998, Foz do Iguaçu. Anais... Foz do Iguaçu: Anpad, 1998. Marketing.
VIEIRA, Francisco G. D. Ações empresariais e prioridades de pesquisa em marketing: tendências no Brasil e no mundo segundo a percepção dos acadêmicos brasileiros. In: ENCONTRO ANUAL DA ASSOCIAÇÃO NACIONAL DOS PROGRAMAS DE PÓS-GRADUAÇÃO EM ADMINISTRAÇÃO, 23ํ, 1999, Foz do Iguaçu. Anais... Foz do Iguaçu: Anpad, 1999 Marketing.

VIEIRA, Francisco G. D. Panorama acadêmico-científico e temáticas de estudos de marketing no Brasil. In: ENCONTRO ANUAL DA ASSOCIAÇÃO NACIONAL DOS PROGRAMAS DE PÓS-GRADUAÇÃO EM ADMINISTRAÇÃO, 24ㅇ, 2000, Florianópolis. Anais... Rio de Janeiro : Anpad 2000. Marketing.

ULRICH, D., Human Resource of the Future: conclusions and observations, Human Resource Management. v.36, n. 1, p. 175-179, 1997

ULRICH, D. Os Campeões de Recursos Humanos: inovando para obter os melhores resultados. São Paulo. Futura,1998.

YIN,R. The abridged version of case study research IN: BICKMAN, L., ROG, Debra (ed), Handbook of Applied Research Methods. London: Sage, 1998.

\section{Maria José Tonelli}

Professora dos cursos de graduação, pós-graduação acadêmica e pós-graduação executiva do Departamento de Administração Geral e Recursos Humanos da FGV-EAESP. Doutora e mestre em Psicologia Social pela PUC-SP. Interesses de pesquisa em recursos humanos e estudos organizacionais. E-mail: mjtonelli@fgvsp.br Endereço: FGV-EAESP. Av. Nove de julho, 2029. CEP 01313-902. São Paulo-SP.

\section{Miguel P. Caldas}

Professor do Departamento de Administração Geral e Recursos Humanos da FGV-EAESP.

Doutor e mestre em Administração de Empresas pela FGV-EAESP. Interesses de pesquisa em teoria das organizações, ensino e pesquisa em administração e comportamento organizacional.

E-mail: mcaldas@fgvsp.br

Endereço: FGV-EAESP. Av. Nove de julho, 2029. CEP 01313-902. São Paulo-SP.

\section{Beatriz Maria Braga Lacombe}

Professora do Departamento de Administração Geral e Recursos Humanos da FGV-EAESP. Doutoranda em Administração de Empresas pela FEA-USP. Mestre em Administração de Empresas pela FGV-EAESP. Interesses de pesquisa em relações de trabalho, carreira e identidade profissional e modelo de gestão de pessoas.

E-mail: bialacombe@fgvsp.br

Endereço: FGV-EAESP. Av. Nove de julho, 2029. CEP 01313-902. São Paulo-SP.

\section{Tatiana Tinoco}

Mestranda em Administração de Empresas pela FGV-EAESP.

Interesses de pesquisa em recursos humanos e ensino e pesquisa em administração.

E-mail: tatianat@fgvsp.br

Endereço: FGV-EAESP. Av. Nove de julho, 2029. CEP 01313-902. São Paulo-SP. 